\title{
Low-Temperature and Low Thermal Budget Fabrication of Polycrystalline Silicon Thin-Film Transistors
}

\author{
Hsiao-Yi Lin, Member, IEEE, Chun-Yen Chang, Fellow, IEEE, Tan Fu Lei, \\ Feng-Ming Liu, Wen-Luh Yang, Juing-Yi Cheng, Hua-Chou Tseng, and Liang-Po Chen
}

\begin{abstract}
A top-gate self-aligned n-channel polycrystalline silicon (poly-Si) thin-film transistor (TFT) has been fabricated with low temperature $\left(\leq 550{ }^{\circ} \mathrm{C}\right)$ and low thermal budget process. The ultrahigh vacuum chemical vapor deposition (UHV/CVD) grown poly-Si was served as the channel film, the chemical mechanical polishing (CMP) technique was used to polish the channel surface, plasma-enhanced chemical vapor deposited (PECVD) tetraethylorthosilicate (TEOS) oxide was used as the gate dielectric, and $\mathrm{NH}_{3}$ plasma was used to passive the device. In this process, the solid phase crystallization (SPC) step is not needed. $A$ field effect mobility of $46 \mathrm{~cm}^{2} / \mathrm{V}-\mathrm{s}$, ON/OFF current ratio of over $10^{7}$, and threshold voltage of $0.8 \mathrm{~V}$ are obtained. The significant reduction in process temperature and thermal budget make this process advantageous for larger-area-display peripheral driver circuits on glass substrate.
\end{abstract}

\section{INTRODUCTION}

$\mathbf{P}$ OLYCRYSTALLINE silicon (poly-Si) thin-film transistors (TFT's) have attracted much attention due to their applications for active matrix liquid crystal displays (AMLCD's) [1]. The key technologies to fabricate TFT's at low temperature are the channel preparation, gate dielectric deposition, and doping process. Conventionally, low-pressure chemical vapor deposition (LPCVD) is used for the deposition of the amorphous film followed by solid phase crystallization (SPC) to transform amorphous films to poly-Si. Usually, the SPC process is time consuming $(15-48 \mathrm{~h})$, which may seriously affect the throughput and thermal budget of fabrication. On the other hand, the high-quality and low-temperature deposited gate dielectric are indispensable. Furthermore, how to reduce the post implant anneal time is important for top-gate self-aligned devices. Recently, many methods have been proposed to: a) prepare the channel film (such as laser annealing [2], depositing poly-Si at reduced pressure [3], and catalyzer-assisted growth [4]), b) deposit gate dielectric (such as electron cyclotron resonance (ECR) chemical vapor

\footnotetext{
Manuscript received January 29, 1996; revised July 8, 1996. This work was supported by the National Science Council, Taiwan, R.O.C., under Contract NSC85-2215-E009-051

H.-Y. Lin, C.-Y. Chang, T. F. Lei, J.-Y. Cheng, and H.-C. Tseng are with the Department of Electronics Engineering and Institute of Electronics, National Chiao Tung University, Hsinchu 300, Taiwan, R.O.C.

F.-M. Liu and W.-L. Yang are with the Department of Electrical Engineering, Feng Chia University, Taichung, Taiwan, R.O.C.

L.-P. Chen is with National Nano Device Laboratories, Hsinchu 300 , Taiwan, R.O.C.

Publisher Item Identifier S 0741-3106(96)08306-1.
}

deposition (CVD) oxide [5], remote PECVD oxide [6], and plasma tetraethylorthosilicate (TEOS) oxide [7]), and c) realize the doping process (such as in situ doping [8], and plasma ion implantation [9]). In the previous work [10], we fabricated new TFT's using ultrahigh vacuum chemical vapor deposited (UHV/CVD) poly-Si film as the channel material followed by a chemical mechanical polishing (CMP) [11]. The gate oxide was grown at $850{ }^{\circ} \mathrm{C}$.

In this work, a top-gate self-aligned TFT was studied. The UHV/CVD deposited poly-Si was used as the channel film and gate electrode, while plasma TEOS oxide was used as the gate dielectric; no long time post implant annealing was needed. The maximum process temperature is under $550^{\circ} \mathrm{C}$.

\section{EXPERIMENTAL}

A $500-\mathrm{nm}$ thermally oxidized silicon wafer was used as the initial substrate. A UHV/CVD system was employed to deposit a $80-\mathrm{nm}$ undoped poly-Si film at $550^{\circ} \mathrm{C}$ as the channel layer followed by CMP. The UHV/CVD system has a base pressure of $10^{-8}$ torr and a deposition pressure of 0.94 mtorr, using $\mathrm{SiH}_{4}$ as the gas source. The CMP system was used to planarize the channel surface. After CMP polishing, the film thickness was reduced to $60 \mathrm{~nm}$, and the rms surface roughness was reduced from 8.0 to $4.2 \mathrm{~nm}$. The grain size is about $80 \mathrm{~nm}$, as determined by plane view transmission electron microscopy (TEM). These films were then defined by a photomask and patterned by a plasma etching for the active area island. A 30-nm gate oxide was then deposited by PECVD at $300^{\circ} \mathrm{C}$ on the channel as the gate dielectric using tetraethylorthosilicate (TEOS) and oxygen as deposition gases. After these steps, a $300-\mathrm{nm}$ undoped poly-Si was deposited by $\mathrm{UHV} / \mathrm{CVD}$ at $550{ }^{\circ} \mathrm{C}$ as the gate material, which was also defined by a photomask patterning and by plasma etching. The gate-electrode and source/drain regions were doped by phosphorus implant at an energy of $50 \mathrm{keV}$ and a dose of $5 \times 10^{15} \mathrm{~cm}^{-2}$. After implantation, a $550^{\circ} \mathrm{C}$ anneal was given at $\mathrm{N}_{2}$ ambient for $4 \mathrm{~h}$. The resistivity is around $8 \mathrm{~m} \Omega-\mathrm{cm}$ of the gate. $\mathrm{A} \mathrm{NH}_{3}$ plasma treatment was then given at $300{ }^{\circ} \mathrm{C}$ with the power density of $0.67 \mathrm{~W} / \mathrm{cm}^{2}$ for $2 \mathrm{~h}$ using PECVD. The $200 \mathrm{~nm}$-thick oxide passivation-layer was also deposited by PECVD system at $300{ }^{\circ} \mathrm{C}$. Finally, contact hole definition and $\mathrm{Al}$ metallization was performed. 


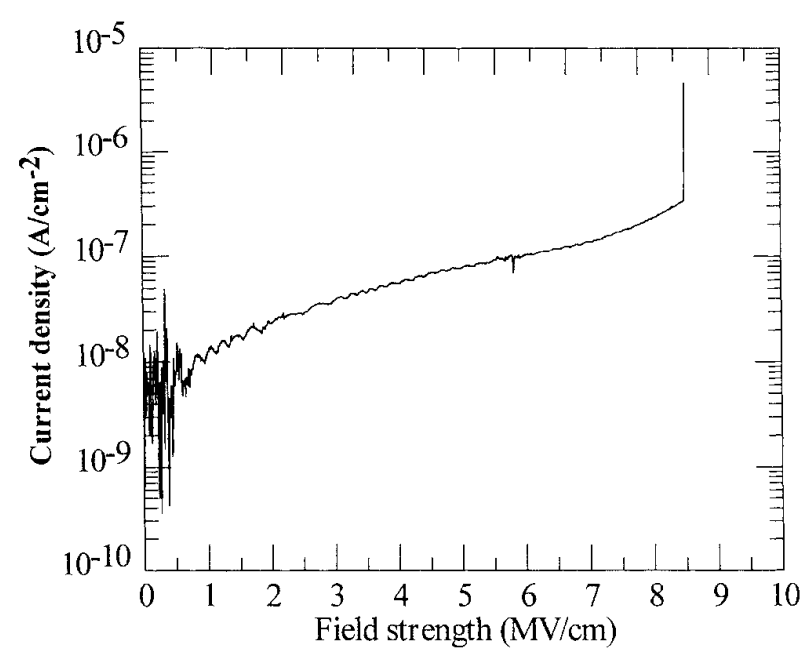

(a)

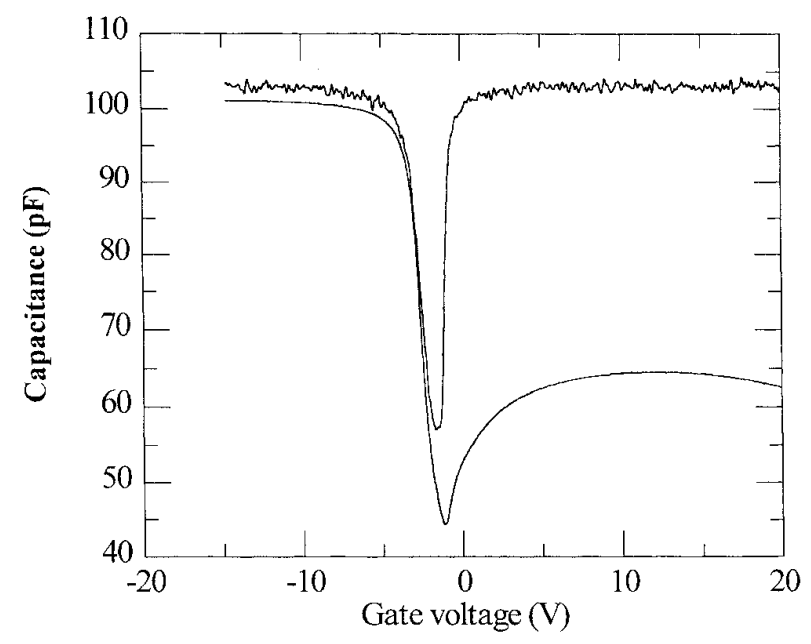

(b)

Fig. 1. (a) The $I V$ characteristics of 100-nm TEOS-oxide films deposited by PECVD at $300{ }^{\circ} \mathrm{C}$ with the TEOS/O $/ 2$ flow ratio of $800: 10$. (b) The quasiand high-frequency $C V$ characteristics. The TEOS oxide was annealed at $400{ }^{\circ} \mathrm{C}$ for $30 \mathrm{~min}$ at $\mathrm{N}_{2}$ ambient. The capacitance for measurement has a area of $7 \times 10^{-4} \mathrm{~cm}^{2}$.

\section{RESULTS AND DISCUSSION}

Fig. 1(a) shows the $I V$ characteristics of the TEOS oxide. The oxide thickness is $100 \mathrm{~nm}$ and was annealed at $400{ }^{\circ} \mathrm{C}$ for $30 \mathrm{~min}$ in nitrogen ambient. The breakdown is defined when the gate current is reaching $1 \mu \mathrm{A} / \mathrm{cm}^{2}$, and we find that the breakdown field is greater than $8 \mathrm{MV} / \mathrm{cm}$. Fig. 1(b) shows the quasi- and high-frequency $C V$ characteristics of the oxide. It is found that the quality of the TEOS oxide is good enough as the gate dielectric. Typical transfer curves of drain currents $\left(I_{\mathrm{d}}\right)$ versus gate voltages $\left(V_{\mathrm{g}}\right)$ are shown in Fig. 2. This figure illustrates the $I V$ characteristics of TFT's with and without $\mathrm{NH}_{3}$ plasma treatment for $2 \mathrm{~h}$. The device has a channel length of $10 \mu \mathrm{m}$ and a width of $50 \mu \mathrm{m}$. After plasma treatment, the performance is dramatically improved. The greatly improved transistor characteristics were not only due to the $\mathrm{NH}_{3}$ passivation, but also due to the improved quality of UHV/CVD grown poly-Si films. More device characteristics

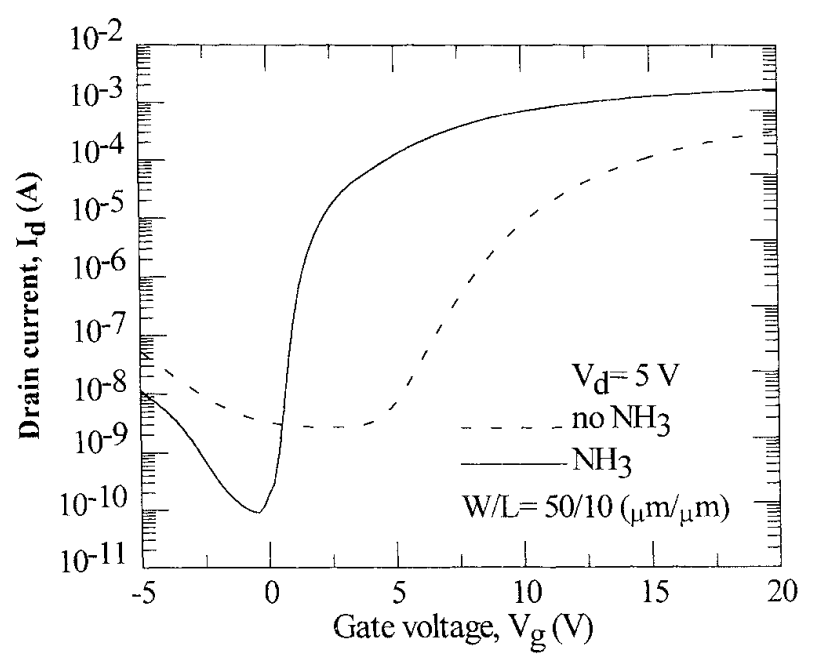

Fig. 2. Typical transfer curves of drain currents versus gate voltages of TFT's with and without $\mathrm{NH}_{3}$ plasma treatment. The device has a channel length of $10 \mu \mathrm{m}$ and a channel width of $50 \mu \mathrm{m}$.

TABLE I

Summary of the TFT Characteristics Shown IN Fig. 2

\begin{tabular}{|c|c|c|c|c|c|c|}
\hline $\begin{array}{c}\mathrm{NH}_{3} \\
\text { Plasma } \\
\end{array}$ & $\begin{array}{c}\mu_{\mathrm{FEE}} \\
\left(\mathrm{cm}^{2} / \mathrm{V}-\mathrm{s}\right)\end{array}$ & $\begin{array}{l}V_{\text {th }} \\
(\mathrm{V})\end{array}$ & $\begin{array}{c}\text { SS } \\
\text { (V/decade) } \\
\end{array}$ & $\begin{array}{c}N_{t} \\
\left(\times 10^{12} \mathrm{~cm}^{-2}\right)\end{array}$ & $\begin{array}{c}\mathrm{I}_{\min } \\
(\mathrm{pA} / \mu \mathrm{m})\end{array}$ & $\begin{array}{c}\text { On/Off } \\
\text { current ration }\end{array}$ \\
\hline - & 15.2 & 7.0 & 1.2 & 6.7 & 54.8 & $1.2 \times 10^{5}$ \\
\hline $2 \mathrm{hr}$ & 46.5 & 0.8 & 0.23 & 1.6 & 1.82 & $1.9 \times 10^{7}$ \\
\hline
\end{tabular}

are summarized in Table I, where the peak field-effect mobility, $\mu_{\mathrm{FE}}$, threshold voltage, $V_{\mathrm{th}}$, subthreshold swing, $S S$, trap density, $N_{\mathrm{t}}$, minimum current, $I_{\min }$, and the on/off current ratio are demonstrated. These values are determined at a drain voltage, $V_{\mathrm{d}}$ of $0.1 \mathrm{~V}$ except the minimum, $I_{\min }$ current and on/off current ratio which are determined at $V_{\mathrm{d}}=5 \mathrm{~V}$. After plasma passivation, the threshold voltage is $0.8 \mathrm{~V}$ which was determined by the $I_{\mathrm{d}}$ versus $V_{\mathrm{g}}$ curve in the linear region at $V_{\mathrm{d}}=0.1 \mathrm{~V}$, the trap density. $N_{\mathrm{t}}$ is $1.6 \times 10^{12} \mathrm{~cm}^{-2}$ which was determined by $\ln \left[I_{\mathrm{d}} /\left(V_{\mathrm{g}}-V_{\mathrm{FB}}\right)\right]$ versus $1 /\left(V_{\mathrm{g}}-V_{\mathrm{FB}}\right)^{2}$ at $V_{\mathrm{d}}=0.1 \mathrm{~V}$. The on/off current is $1.9 \times 10^{7}$ and was determined by the gate voltage swing of $20 \mathrm{~V}$ and a $V_{\mathrm{d}}$ of $5 \mathrm{~V}$. The low threshold voltage, subthreshold swing, and trap density, in such a small grain $(\sim 80 \mathrm{~nm})$ poly-Si TFT, indicate that the UHV/CVD grown poly-Si film is of high quality and can be effectively passivated by $\mathrm{NH}_{3}$ plasma treatment.

\section{CONCLUSIONS}

In summary, a new process has been developed for fabricating poly-Si TFT's at low temperature and low thermal budget on glass substrate. This process uses UHV/CVD to deposit the channel film, CMP technique to planarize the channel surface, TEOS oxide as the gate dielectric, and $\mathrm{NH}_{3}$ plasma to passive the device. Our results reveal that the usage of these techniques on the device fabrication would be a powerful approach to realize low-temperature, low thermal budget, and high-throughput process steps. Further study in device process and oxide quality requirements are essential for higher performance devices. 


\section{ACKNOWLEDGMENT}

The authors would like to thank the staff of Semiconductor Research Center, National Chiao Tung University, for technique help.

\section{REFERENCES}

[1] H. Ohshima and S. Morozumi, "Future trends for TFT integrated circuits on glass substrates," in IEDM Tech. Dig., 1989, vol. 89, p. 157.

[2] A. Kohno, T. Sameshima, N. Sano, M. Sekiya, and M. Hara, "High performance poly-Si TFT's fabricated using pulsed laser annealing and remote plasma CVD with low temperature processing," IEEE Trans. Electron Devices, vol. 42, pp. 251-257, 1995.

[3] H. C. Lin, H. Y. Lin, C. Y. Chang, T. F. Lei, P. J. Wang, R. C. Deng, J. Lin, and C. Y. Chao, "Deposition and device application of in situ boron-doped polycrystalline SiGe films grown at low temperatures," $J$. Appl. Phys., vol. 74, p. 5395, 1993.

[4] H. Matsumura, K. Mimura, and H. Makino, "Low-temperature formation of high-mobility polysilicon TFT by cat-CVD method," in Int. Workshop Active-Matrix Liquid-Crystal Display, Proc. AMLCD 95, Japan, 1995, pp. 89-92.

[5] T. W. Little, K. Takahara, H. Koike, T. Nakazawa, I. Yudasaka, and H. Ohshima, "Low temperature poly-Si TFT's using solid phase crystallization of very thin films and an electron cyclotron resonance chemical vapor deposition gate insulator," Jpn. J. Appl. Phys., vol. 30 , no. $12 \mathrm{~B}, \mathrm{pp} .3724-3728,1991$.

[6] M. Sekiya, M. Hara, N. Sano, A. Kohno, and T. Sameshima, "High performance poly-crystalline silicon thin-film transistors fabricated using remote plasma chemical vapor deposition of $\mathrm{SiO}_{2}$," IEEE Electron Device Lett., vol. 15, no. 2, pp. 69-71, 1994.

[7] Y. Nishi, T. Funai, H. Izawa, T. Fujimoto, H. Morimoto, and M. Ishii, "Characteristics of plasma-enhanced-chemical-vapor-deposition tetraethylorthosilicate oxide and thin-film transistor application," Jpn. J. Appl. Phys., vol. 31, no. 12B, p. 4570, 1992.

[8] L. Pichon, F. Raoult, O. Bonnaud, J. Pinel, and M. Sarret, "Low temperature $\left(<600^{\circ} \mathrm{C}\right)$ polysilicon thin-film transistors having in-situ doped polysilicon source and drain contacts," IEEE Electron Device Lett., vol. 16, no. 9, pp. 376-378, 1995.

[9] J. D. Bernstein, S. Qin, C Chan, and T. J. King, "Hydrogenation of polycrystalline silicon thin-film transistors by plasma ion implantation," IEEE Electron Device Lett., vol. 16, no. 10, pp. 421-423, 1995.

[10] C. Y. Chang, H. Y. Lin, T. F. Lei, J. Y. Cheng, L. P. Chen, and B. T. Dai, "Fabrication of thin-film transistors by chemical mechanical polished polycrystalline silicon films," IEEE Electron Device Lett., vol. 17, no. 3, pp. 100-102, 1996.

[11] M. Cao, S. C. Kuehne, K. C. Saraswat, and S. S. Wong, "A low thermal budget polysilicon thin-film transistor using chemical mechanical polishing," in SID Conf. Record 1994, Int. Display Research Conf. Int. Workshops on Active Matrix LCD's and Display Materials, Monterey, CA, Oct. 1994, pp. 294-297. 